\title{
Revista Innova Educación
}

\author{
WWW.revistainnovaeducacion.com
}

ISSN: 2664-1496 ISSN-L: 2664-1488

Editada por: Instituto Universitario de Innovación Ciencia y Tecnología Inudi Perú

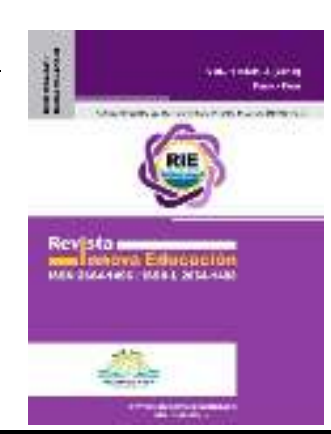

\section{La intertextualidad en egresados de educación básica}

\author{
Intertextuality in graduates of basic education \\ Fernando Ledesma-Pérez ${ }^{1}$ \\ Universidad César Vallejo, Cañete - Lima, Perú \\ (D) https://orcid.org/0000-0002-9954-1813 \\ Juana Cruz-Montero \\ Universidad César Vallejo, Cañete - Lima, Perú \\ https://orcid.org/0000-0001-8613-5595 \\ María Caycho-Ávalos \\ Ministerio de Educación, Lima - Lima, Perú \\ (D) https://orcid.org/0000-0003-0624-2636 \\ Renee Rosales-Llontop \\ Universidad César Vallejo, Cañete - Lima, Perú \\ (D) https://orcid.org/0000-0002-5473-9797
}

DOI: https://doi.org/10.35622/j.rie.2020.03.006

Recibido 25/06/2020/ Aceptado 25/07/2020 Publicado 25/07/2020

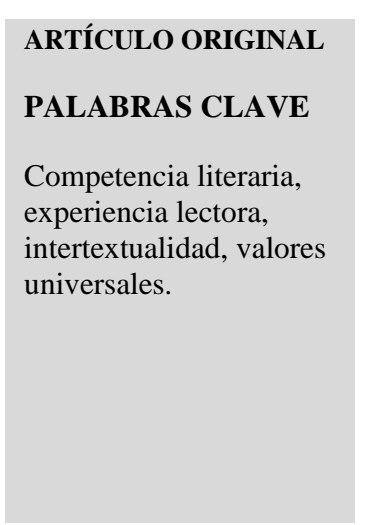

\section{KEYWORDS}

Intertextuality, literary competence, reading experience,
La intertextualidad, como entrecruzamiento de un significado con otro, se refiere a la vinculación con otros textos y a los aportes que hacen para ofrecer varias posibilidades interpretativas y creativas. Se considera elemento central de la complejidad de relaciones conceptuales y semánticas para dotar de sentido la comunicación, incorpora y valida la cultura del sujeto en el proceso de democratización para comprenderla y participar en la misma. Esta investigación se realizó en egresados de educación básica regular para mensurar el dominio de la intertextualidad. Se emplearon dos lecturas en prosa, ambas del escritor y poeta César Abraham Vallejo Mendoza, (1) Los Caynas, y (2) Más allá de la vida y la muerte. Para el recojo de información se eligieron indicadores comportamentales observables y medibles, se utilizó la observación y una lista de cotejo. Se encontró que el 62,1\% se ubicó en el nivel bajo, el 29,3\% en el nivel alto y el 8,6 \% en el nivel medio. Se recomienda que en futuras investigaciones se trabaje con muestras representativas para comparar y explicar la competencia literaria y experiencia lectora que serían elementos básicos de la intertextualidad.

\footnotetext{
${ }^{1}$ Correspondencia: fledesma@ucv.edu.pe
}

Intertextuality, as a cross-linking of one meaning with another, refers to the link with other texts and the contributions they make to offer various interpretative and creative possibilities. It is considered a central element of the complexity of conceptual and semantic relationships to give meaning to communication, it incorporates and validates the culture of the subject in the democratization process in order to understand and participate in it. This research was carried 
ideas, universal values out graduates of regular basic education to measure the domain of intertextuality, two prose readings were used, both by the writer and poet César Abraham Vallejo Mendoza, (1) Los Caynas, and (2) Beyond life and death, for the collection of information observable and measurable behavioral indicators were chosen, observation and a checklist were used. It was found that $62.1 \%$ was at the low level, $29.3 \%$ at the high level and $8.6 \%$ at the medium level. It is recommended that in future investigations, representative samples be used to compare and explain the literary competence and reading experience that would be basic elements of intertextuality.

\section{INTRODUCCIÓN}

La intertextualidad como técnica es un proceso cognitivo que permite al sujeto que lee, identificar convergencias del texto con saberes anteriores asimilados a lo largo del tiempo; se trata de una característica común a todos los sujetos, constituyéndose en una regularidad, de allí que la comprensión de los sucesos o fenómenos ocurre solo cuando existen saberes anteriores, los cuales pueden aparecer incluso de forma inconsciente. En esta investigación, el comportamiento de los egresados de educación fue observado en la primera y segunda dimensiones y para la tercera dimensión. Se empleó una escala estimativa que contenía los criterios para la determinación de la trayectoria de sus conocimientos. Lo que dotaba al sujeto de un repertorio de saberes para adoptar una actitud comprensiva e interpretativa de las dos lecturas asignadas: Los Caynas y Más allá de la vida y de la muerte; y en función a ello le asignaba un juicio de valor a dichos textos.

Las coincidencias de teóricos como Lotman (1996), Barthes (2002) y Montaño (2002) apuntan a la intertextualidad como un nodo en el que confluyen distintos códigos, de diversas culturas, que tuvieron auge en un determinado período, lo que conlleva al encuentro de un texto dentro de otro y permite al lector asignarle sentido al mensaje; se configura como un entretejido de voces que emergen con diferentes códigos vinculados a lo escuchado, visto o leído que tiene registro en el repertorio de experiencias y vivencias del sujeto. Es la recuperación de la diacronía para la interpretación de la sincronía en un contexto vigente. Kasper \& Singer (1997), MartínBarbero \& Rey (1999) propusieron que los intertextos participan de la formación de mapas cognitivos. En ese sentido, al ocurrir la incorporación de un mensaje, este se convierte en un mapa intertextual y logra su concreción en la competencia comunicativa del sujeto; la interpretación textual resulta de un acto social y cultural incrustado, ligado a los múltiples escenarios en los que el sujeto se desenvuelve y la comprensión del mensaje involucra acontecimientos sociales mediados por experiencias particulares, sean estas perceptuales, afectivas o valorativas.

La intertextualidad se incorpora a la educación básica como componente de la competencia comunicativa debido a su utilidad para complejizar y ampliar el horizonte de la 
red de relaciones tanto en el ámbito conceptual como semántico que facilite el completamiento de sustento social y cultural para darle sentido al texto (Aguilar, 2008). Buckingham (2004) considera que la intertextualidad no se limita solo a elementos de semántica, sino que, en tanto aporta a la competencia comunicativa que contribuye a la democratización del sujeto, valida su cultura, facilita su participación en la vida social y cultural.

La asociación de la intertextualidad con la competencia literaria fue mencionada tanto por Bajtin (1976) como por Genette (1982) quienes encontraron que los géneros literarios muestran sucesivas iteraciones, referencias a otros textos e incluso citan de manera implícita. En ese sentido, el significado que el sujeto le asigne al texto tiene relación directa con la competencia literaria, si el sujeto carece de referencias sobre otros textos no es posible la intertextualidad. En esta lógica de ideas, Mendoza Fillola (2001) hizo referencia a los textos que resultan muy atractivos para algunos sujetos, pero incomprensibles para otros, situación que se explica porque quien no comprende los textos carece de referencias para la valoración de la estética y contenido del texto.

El mecanismo a partir del cual se construye el sentido del mensaje al que se accede queda determinado por la totalidad de las redes de significados entretejidas en la trayectoria vital del sujeto a partir de su experiencia o de su participación en la resolución de problemas. Carbonell (2002), la intertextualidad se constituye en un nudo en el que se entrecruzan un significado con otro, significa la vinculación con otros textos y la riqueza, tanto de la interpretación como de la creación. Sin embargo, Guillén (1985) se refirió a los obstáculos, a los malos entendidos e incluso a las trampas que contiene la intertextualidad y que convierte en dificultosas las relaciones literarias entre autores de diversas nacionalidades, varios textos literarios son en realidad intertextos y se les confunde con influencia literaria y resulta complejo deslindar entre intertexto e influencia por la falta de criterios y por la trayectoria del revisor.

La primera dimensión es la competencia literaria, Díaz (2009) dijo que es un complejo proceso de construcción de la comprensión e interpretación del texto y como competencia implica de manera fundamental la interpretación del contenido, la cual es una actividad cognitiva que requiere elementos adicionales a la comprensión. Mendoza Fillola (2008) acotó que la interpretación requiere para su elaboración del enlazamiento del conocimiento de los valores formales y semióticos del texto con las reacciones cognitivas y afectivas que éste genera en el lector. Dilthey (1986) desde su propuesta en ciencias comprensivas sostuvo que es necesario 
comprender primero para luego hacer una interpretación dentro del marco teórico del que dispone el sujeto.

La segunda dimensión es la experiencia lectora, Díaz (2009) indicó que es la depositaria de la progresiva, sucesiva selección, acumulación de saberes y conocimientos disponibles para la comprensión y enriquecimiento del intertexto adquirido a través del aprendizaje de determinados conocimientos. Mendoza Fillola (2008) precisó que la lectura trasciende el texto, implica comprensión, identificación y análisis de los componentes relativos tanto de la obra como de su contexto. González Nieto (1992), García Ribera (1996), Díaz-Plaja (2002) citados por Mendoza Fillola (2008) coincidieron en que la literatura no es compendio de saberes teóricos, su objeto se orienta al fomento de la participación activa de los lectores a la valoración e interpretación de la obra.

La tercera dimensión es la identificación de ideas y valores universales; Díaz (2009) señaló que luego de la interpretación del texto, este se convierte en pretexto para la búsqueda de valores o ideas universales con los que el sujeto se identifique o se sienta próximo; el texto sirve para el descubrimiento de los componentes con alcance universal; se identifican los valores atemporales, que han estado presentes en todos los tiempos y siguen vigentes, superando el prejuicio que los valores caducan y pasan de moda.

El bajo nivel o ausencia de bagaje y soporte intertextual pone en evidencia que no fue incluido este elemento dentro de los alcances de la competencia comunicativa durante el proceso de educación básica, por lo que su enseñanza y evaluación no fueron consideradas dentro de los aprendizajes previstos en la microprogramación, pese a estar incorporados dentro de los desempeños del área de comunicación desde el último grado de primaria y en todos los grados del nivel secundaria (Ministerio de Educación -Minedu, 2016a y Minedu, 2016b).

Los egresados de educación básica muestran dificultades para la lectura fluida y comprensiva, que van desde bajos niveles de atención, concentración, niveles reflexivos elementales sobre el contenido, incapacidad para la identificación de matices y soslayo de los giros lingüísticos. Estas limitaciones impiden la construcción de la comprensión del texto, que además requiere dominio del idioma, conocimiento del significado de las palabras para entender las frases y la concatenación de frases para la identificación del mensaje por párrafo siguiendo la secuencia de su redacción. La comprensión es el paso previo a la interpretación, la cual se construye desde una particular visión desde la que se da el marco para la emisión de un juicio de valor, este marco 
de interpretación es producto de la intertextualidad, la semejanza con textos del mismo género e incluso por variantes argumentativas.

Los egresados reportan una pobre experiencia lectora tanto de literatura nacional como universal, los pocos textos leídos lo hicieron por obligación y sujetos a calificación en el área de comunicación, el número de egresados que leyó por iniciativa propia gira alrededor del 5 por ciento; esta inexistencia de competencia literaria les impide el análisis y la comprensión intertexual de las lecturas. Para los egresados con falta de experiencia lectora pueden parecerle novedosos ciertos temas, no porque lo sean, sino porque carecen de un marco para su comprensión.

Los valores a la vida, libertad, dignidad, verdad y justicia son regularidades en todas las obras y en todos los tiempos, representan principios universales respecto a los cuales no cabe ninguna discusión, aparecen con la humanidad sea cual fuere la fuente; sin embargo, los egresados los desconocen. El castigo, terrenal o divino siempre acompaña a las malas acciones y los premios a los actos buenos; las rebeliones, los grupos contestatarios siempre surgieron como respuesta a los opresores y las grandes transformaciones solo ocurrieron después de conflictos; estas son otras regularidades presentes en los textos y por tanto se constituyen en pautas universales para su comprensión independientemente de la época en que ocurrieron; sin embargo, el desconocimiento de las tramas y los mensajes de los textos colocan a los egresados en una condición de precariedad en competencia literaria sin posibilidad de emplear el recursos de la intertextualidad.

Los egresados de educación básica evidencian que la competencia literaria no se alcanzó. Sus niveles de lectura son funcionales y el repertorio de términos empleados en su comunicación cotidiana es limitado; la inatención y la escasa retención de lo leído es frecuente; su experiencia lectora se limita a los libros que les obligaron a leer de los cuyos contenidos mantienen recuerdos confusos, lo cual no aporta a la construcción de sentido de nuevas lecturas; la escala de valores universales que sirve para la emisión de juicios de carácter moral, ético, social, son restringidas y solo alcanzan al contexto en que se desenvuelven. No se encontraron elementos que indiquen participación en concursos literarios, ferias de libros, debates sobre autores, que favorezcan la fundamentación de sus ideas. La contraargumentación es un fenómeno dialéctico que exige la asunción de una postura y solo se alcanza con la competencia comunicativa de la intertextualidad.

En las investigaciones previas se encontró que Schöngut Grollmus \& Pujal Llombart (2014) hicieron un trabajo de corte feminista para aproximarse a la intertextualidad en el dolor crónico desde la perspectiva de género, trabajo cualitativo y concluyeron que el género es una práctica y es un producto en forma simultánea. La intertextualidad aparece como una estructura 
por términos y actos del lenguaje cuya existencia es anterior al relato y a la narrativa y seguirá existiendo; en ese mismo sentido Graham (2000) dijo que, si la escritura está hecha de pedazos de la realidad social, entonces refleja las tensiones propias de la ideología que las sustentan. Solá (2005) comparó la producción de dos autores para ver la confluencia identitaria canónica y en ambos casos encontró reescritura que es equivalente a intertextualidad, si bien existían sentidos diferentes, eso no descartaba la influencia de textos previos, sino el particular entendimiento de cada autor que está determinado por su formación cultural, mientras más breve y exigua la trayectoria del autor más limitada es su producción.

Tyner (2008) investigó la alfabetización en medios eligiendo como variable predictora la intertextualidad, sostuvo que esta variable es un puente para la alfabetización con recursos on-line, permite flexibilidad, interactividad, análisis y producción en línea; ofrece múltiples textos para favorecer la integración colectiva del conocimiento, permitiendo la alfabetización en intertextualidad a través de la web. Becerra (2010) investigó la intertextualidad en la lectura detectivesca "Como el aire de abril" de Arturo Echavarría, encontró que recurrió a la intertextualidad para la urdimbre de un complejo rompecabezas literario con situaciones de suspenso y espera a ser resuelto; el lector que sigue las pistas del crimen debe recurrir al conocimiento de la cábala de otros autores como Dante, Neruda, Borges, Cristóbal Colón entre otros; las coincidencias a lugares y personajes es recurrente, una ciudad se parece a otra y un personaje es el alter ego de otro con nombres alterados; el nivel de intertextualidad impregna a la novela de principio a fin.

Níkleva (2013) investigó la intertextualidad en las áreas de lengua y artes para la identificación de las relaciones entre intertextualidad e intermedialidad, lenguaje y cultura, consideró la interpretación intersistémica (empleo uso de múltiples códigos semióticos para interpretar un mensaje); encontró limitaciones en la precisión de los conceptos intertextualidad y competencia textual, así mismo no estaba claro el deslinde conceptual entre texto e intertexto, las dificultades las superó con definiciones operacionales y encontró que la relación entre lengua y artes (pintura, cine, música, museos) está determinada por las unidades simbólicas de comunicación cultural que corresponden a una lengua o un ámbito cultural. Looft (2018) hizo un trabajo sobre la producción de la escritora y feminista austriaca Rosa Mayreder, concluyó que en su prolífica producción empleó la técnica de intertextualidad como símbolo estratégico de resistencia hacia un hombre dominado por los hombres, destacó en el contenido de su obra los derechos de las mujeres a la educación, los cambios generacionales, las situaciones de conflicto y cambio social; en la actualidad la influencia de la intertextualidad de su obra sigue causando 
asombro. Hugo Rojas, Leiva Salum, Marchant Moreno, Gallegos Pérez y Toro Trengove (2018), realizaron un trabajo sobre uso de citas como elemento de intertextualidad en universitarios principiantes, se analizaron fragmentos de 30 ensayos para identificar la presencia de la intertextualidad, encontraron citas textuales y parafraseo, no se encontraron avances en literalidad, precisión del mecanismo e integración sintáctica, fenómeno explicado por la práctica docente universitaria, la que prioriza las citas textuales y parafraseos, en las que el estudiante debe ser portador de la voz del otro y no promueve la intertextualidad.

Elouise Budag (2019) investigó la dimensión discursiva y dentro de ella el análisis de la forma en la que operaba la intertextualidad en una serie televisiva difundida en señal abierta, abordó elementos verbales e imaginarios y encontró que en la mayoría de escenas se producían referencias intertextuales, por lo que afirmó que la intertextualidad no solo ocurre en el elemento discursivo y concluyó que existe construcción y producción de escenas intertextuales, en cuya composición conviven imágenes externas e internas mediante la inserción de imágenes asociadas a los saberes de los televidentes que incluyen elementos imaginarios, ficticios y los roles de los agentes. Haixia Yang y Liqing Kang (2019) seleccionaron la novela estadounidense Blancanieves y encargaron a eruditos chinos realizar tres análisis: (a) vehículos teóricos de la deconstrucción, (b) intertextualidad, y (c) narratotología cognitiva; se recurrió al texto original de la novela (Alemania 1813) y al cuento de hadas de 1965 inspirado en la novela; las traducciones son diversas y la interpretación se hace en el marco del género que se le atribuye así como en las variantes lingüísticas del traductor, concluyeron que las interpretaciones están determinadas por la formación y trayectoria de cada traductor o intérprete y no existe una forma única.

Goswami (2019) investigó la postura cognitiva que adoptan los lectores ante la intertextualidad, eligió el poemario de Jibanananda Das con la incorporación de elementos de la pragmática y la lingüística cognitiva proporcionados por los estudios críticos de Bengalí, encontró que la intertextualidad es una realidad cognitiva y contextual, en la poesía hace alusión a personajes literarios, concluye que la intertextualidad no es una propiedad del texto, sino, se trata de una modalidad cognitiva de percepción, como se aprecia en los poemas de Jibanananda Das en los que la intertextualidad es abundante y creativa. Li (2019) estudio la intertextualidad desde el marketing para asociada a campañas publicitarias de Nike y Adidas ocurridas en el 2008 en la República China y encontró que en efecto funciona como como mediadora en la estrategia de glocalización dentro del mercado global y es aplicable a la comunicación publicitaria, así mismo encontró que existe influencia intertextual en las orientaciones y valores de los grupos afines. 
Esta investigación es importante porque los egresados de educación básica deben ser competentes para comunicarse y se espera que continúen con estudios superiores, para lo cual se requiere el dominio de la intertextualidad para insertarse a la cultura universitaria, los egresados que muestran la capacidad la adquirieron en escenarios distintos al salón de clases. La intertextualidad debe ser de dominio colectivo, la vinculación de unos textos con otros y el reconocimiento de otros textos dentro de un texto debe formar parte de la trayectoria del sujeto como tránsito a la democracia y participación plena y que lo dote de la capacidad para la comprensión e interpretación de los textos. Es necesario que la intertextualidad forme parte de las capacidades evaluadas en los estudiantes, debido a su valor para el entendimiento de los mensajes que están disponibles en diversas plataformas y que requieren la identificación, comprensión, interpretación y valoración, para ser aceptados o desechados en el proceso de aprendizaje de nuevos saberes y ajustados a las ideas y los valores universales.

Esta investigación se orienta a la determinación del nivel de dominio de un repertorio intertextual en egresados de educación básica.

\section{MÉTODO}

Se empleó el enfoque cuantitativo, tipo básico, nivel descriptivo, no experimental y transversal. La muestra fue no probabilística intencional de 58 egresados de educación básica con proyectos de continuar educación superior.

Se seleccionaron dos obras cortas del escritor y poeta peruano César Abraham Vallejo Mendoza: Los Caynas y Más allá de la vida y la muerte, las que fueron impresas y entregadas a cada participante de la investigación, además se les envió por correo electrónico. En un file se le entregó una hoja con las instrucciones en la se precisaba que una vez leídas y releídas debían compararlas con otras obras literarias (leídas, escuchadas o vistas) y encontrar en ellas semejanzas y diferencias. Se indicaba que podían recurrir a diccionarios, internet, consultar a docentes de literatura u otras personas para completar la actividad. El tiempo límite de entrega fijado fue de ocho días.

Las tres siguientes páginas contenían la prueba de ejecución para medir intertextualidad y de cuyo análisis se extraían las respuestas para contrastarlas con la escala estimativa y anotar las respuestas en la lista de cotejo que consta de 24 ítems. La distribución de las hojas fue la siguiente:

En la segunda hoja había una encuesta exploratoria sobre experiencia lectora con seis preguntas abiertas: (1) Mencione los libros que leyó en su trayectoria escolar, (2) Mencione otros libros leídos, (3) Mencione el nombre de las cinco películas que más le hayan gustado, (4) Qué 
tipo de redacción literaria ha realizado, (5) Cuál es el elemento común entre lo leído, visto y escrito, y (6) Cuál es el mensaje común de las obras.

La tercera hoja contenía un cuadro en la que debían anotarse las semejanzas de las dos lecturas dadas, dentro de las que estaban escritas en forma vertical: (1) Argumento, (2) Personajes, (3) Desenlace, (4) Función de la sorpresa, (5) Función del amor filial, y (6) Función del ser supremo. El mismo cuadro contenía de manera horizontal: (1) Los Caynas, (2) Más allá de la vida y la muerte, (3) ¿Por qué hay semejanzas?, (4) Con qué obras se relaciona, y (5) Con qué películas se relaciona. En la parte inferior de la página podían escribir sus comentarios.

La cuarta hoja contenía un cuadro en la que debían anotarse las diferencias las dos lecturas dadas, bajo los mismos criterios que las semejanzas. Estos datos fueron analizados y con ello se respondió la lista de cotejo, la cual fue validada por expertos y mostró una fiabilidad de ,982 (Alpha de Cronbach).

Las respuestas que emitieron los egresados requerían competencia literaria, lo que implicaba, dentro de otros elementos, saber quién es el autor, cuáles son sus orígenes y cuáles las características predominantes de su obra; la lectura moviliza procesos cognitivos superiores como la atención, la concentración, el dominio del idioma, entre otros, la reflexión sobre los acontecimientos, sobre los padres, sobre los escenarios, el tiempo y espacio literarios. El proceso de comprensión requiere saber cómo fue la vida en el ande en el siglo pasado en la que se escribieron las obras literarias; este proceso de interpretación requiere a su vez, tener conocimientos del colonialismo, de los problemas sociales de la comunidad, de los viajes agotadores y trabajos humillantes. Sin estos elementos resulta incomprensible la obra vallejiana.

Operacionalización de la variable

\begin{tabular}{|c|c|c|}
\hline Variable & Dimensiones & Indicadores \\
\hline \multirow{10}{*}{ La intertextualidad } & \multirow{3}{*}{ Competencia literaria } & Lectura atenta y reflexiva de la obra \\
\hline & & Construcción de la comprensión \\
\hline & & Construcción de la interpretación \\
\hline & \multirow{4}{*}{ Experiencia lectora } & Selección progresiva de lecturas \\
\hline & & \\
\hline & & Acumulación de conocimientos \\
\hline & & Enriquecimiento con varios textos \\
\hline & \multirow{3}{*}{$\begin{array}{l}\text { Identificación de ideas y } \\
\text { valores universales }\end{array}$} & $\begin{array}{l}\text { Componente ejemplarizante y universal de la } \\
\text { literatura }\end{array}$ \\
\hline & & Asunción de postura dialéctica en el aula \\
\hline & & Interdisciplinariedad \\
\hline
\end{tabular}




\section{RESULTADOS}

Los resultados de la encuesta exploratoria sobre experiencia lectora como requisito para la competencia literaria e intertextualidad evidenciaron que el 96,6\% leyó menos de 15 libros o textos escolares en 11 años de educación básica, un 98,3\% precisó que leyó menos de 15 libros no escolares durante su infancia y adolescencia. En cuanto al contenido de las películas, el 29,3\% visualizó películas de contenido romántico, el 27,6\% de acción y el 12,1\% refirió haber visualizado películas de ficción, las cuales no aportaban argumentos para comprender las dos obras vallejianas encargadas. Respecto al tipo de texto o género de las obras leídas, el 46,6 \% respondió que al género literario y el 44,8\% no respondió. Conforme han señalado investigadores de esta temática como Sánchez (2016) quien realizó una investigación sobre las implicancias de la intertextualidad en el proceso lector, consideró que esta se convierte en una herramienta de participación activa y creativa de los estudiantes; en la que se tiene en cuenta el valor de polifonía y polidireccionalidad de los textos literarios, desde el intertexto del propio texto y toma en consideración el intertexto del lector, en cuyas implicaciones didácticas se les debe dar la palabra y la libertad para crear y generar intertextos. En el mismo sentido se pronunció Martínez (2017) quien estudió la intertextualidad en la obra narrativa de Miguel Espinosa y resalta que en dicha producción están presentes en gran medida la intratextualidad y la intertextualidad en toda la nutrida e intrincada relación con textos de autores y épocas distintas, con lo cual, para llegar a un grado de producción de textos se requiere la lectura previa de un elevado número de textos vinculados a la temática. De ello, se desprende que el fracaso en la intertextualidad se explica en gran medida por la falta de la competencia literaria.

Ante la pregunta que medía intertextualidad, con elementos comunes entre el contenido de las obras leídas y su experiencia de vida, en el entrecruzamiento entre lo visto, escuchado y leído, el 58,6\% no respondió, el 29,3\% mencionó tres o menos elementos en común y el 12,1\% cuatro o más elementos que se relacionan en su experiencia. Estos resultados están bastante alejados de lo que propone Navarro (2015) quien desde su investigación respecto a la intertextualidad, literatura y bellas artes en José Lucas, refiere que se trata de un acto de valores heterosémicos de la obra, por su encuentro intertextual con el mundo artístico del autor y con el mundo estético del lector; la intertextualidad emerge como el reconocimiento y comprensión del alcance poliédrico de su producción en diversos aspectos y textos como pretextos poéticos que los une; e interpreta su pintura ecfrástica como elemento mediador entre el cuadro y la realidad, implica la comprensión 
de la poesía y la pintura que se fusionan con un conglomerado de una tradición en ambas esferas. Lo mismo mencionó García (2017) quien analizó la obra Una impecable soledad de Luis Hernández con la finalidad de profundizar en las distintas dimensiones del fenómeno intertextual y reflexionar sobre las posibilidades de diálogo que se establecen entre las referencias insertadas al texto y la condición material de los manuscritos, el autor recurre a su propio método de escritura ológrafo, dándole a la obra un carácter metaficcional con lo cual alcanza una compleja trama intertextual.

Ante la pregunta cuál es el mensaje común entre las dos obras vallejianas leídas, el 62,1\% no respondió, el 27,6 \% precisó que había tres o menos elementos comunes y el 10,3 \% encontró cuatro o más elementos en común. Diversos investigadores sostienen que el análisis intertexual implica la identificación de elementos comunes entre las obras comparadas, así se tiene que de Vicente-Yagüe y Guerrero (2014) realizó una investigación desde la teoría crítica literaria en la que refiere que los mensajes comunes son frecuentes en la literatura los cuales los localizó en el análisis de referentes intertextuales literario-musicales lo que pone en evidencia que existe un abordaje desde un modelo interdisciplinar. Así mismo, Arrieta (2015) desarrolló una investigación comparativa entre literatura brasilera y japonesa y encontró que había una presencia permanente de hipotextos en las distintas interpretaciones cinematográficas, así como reflexiones teóricas acerca de las relaciones interartísticas o intermediales entre cine y literatura. En ambos autores se comprueba que los mensajes generan la intertexualidad y no necesariamente las frases, toda vez que corresponden a expresiones idiomáticas distintas.

Para una aproximación al soporte de intertextualidad que presentaba cada egresado, se realizó el análisis de contenido de los dos cuadros comparativos; sobre semejanzas se encontró que el 46,6 \% dejó en blanco los cuadros, el 27,6 \% encontró cinco o más semejanzas y el 25,9 \% encontró cuatro o menos semejanzas entre las lecturas. En cuanto a las diferencias se encontró que el $50 \%$ dejó en blanco los cuadros, el 29,3 \% encontró cinco o más diferencias y el 20,7 \% encontró cuatro o menos diferencias en las lecturas. La identificación se semejanzas es básica para la determinación de las relaciones intertextuales tal como sostuvo Amoretti (1996) quien asumió una postura sociocrítica de la intertextualidad en la crítica contemporánea, precisó que existen contradicciones internas, sostuvo debe examinarse la intertextualidad como parte de una política cultural, como la emergencia de una noción que va más allá del paradigma global en el que se inscribe el saber general; citó a Foucault quien sostuvo que existe una relación visible en el que las obras puedan definirse unas a otras frente, al lado y a distancia de las otras, apoyándose a la vez en su diferencia y simultaneidad, y definiendo sin privilegio ni culminación la extensión de 
una red. En el mismo sentido se pronunciaros Hanson y Gurr (1981) quienes realizaron una sistematización del trabajo de dos autores uno ruso y el otro neozelandés para establecer las diferencias más significativas en su obra literaria, encontraron que las semejanzas eran evidentes: ambos trataron de introducir las perspectivas marginales dentro del canon literario dominante (la rusa y neozelandesa), cultivaron un género literario marginal al que dotaron de un alto prestigio (el relato corto), y se dedicaban a facilitar las preguntas sin ofrecer las respuestas.

Los resultados del procesamiento de datos de la lista de cotejo sobre intertextualidad, mostraron que el 62,1 \% se ubicó en el nivel bajo, el 29,3\% en el nivel alto y el 8,6 \% en el nivel medio, el grupo que se ubicó en el nivel alto había accedido a sucesivas lecturas en escenarios ajenos a la educación básica por lo que este porcentaje no es posible atribuirlo a la acción educativa formal. Estos resultados difieren de los encontrados por Romero y Fierro (2016) quienes investigaron sobre la intertextualidad y la enseñanza de la literatura en preuniversitarios, desde la aplicación de un programa de tres etapas: (1) aproximación inicial a la obra, (2) comprensión desde la relación con otros textos y (3) re-creación de la obra desde una lectura creadora y concluyeron que la intertextualidad cual posibilita la interpretación de los significados del texto literario en sus múltiples y variadas interrelaciones con otros contextos. Del mismo modo, estos resultados son coherentes con el Informe de evaluación de Lectura en sexto grado - 2013, publicado en el Perú por el Ministerio de Educación, en el cual nombran el término intertextualidad, ofrecen recomendaciones, pero no presentan ningún resultado.

La evaluación de la competencia literaria incluyó indicadores sobre lectura atenta y reflexiva, procesos cognitivos empleados para la construcción de la comprensión y, marco social y cultural para la interpretación, los resultados mostraron que el 62,1 \% se ubicó en el nivel bajo, el $31 \%$ en el nivel alto y el 6,9\% en el nivel medio; los resultados tienen relación con lo encontrado por Vega (2017) quien investigó sobre con estudiantes de secundaria sobre el desarrollo de la competencia literaria desde una perspectiva hermenéutica y encontró que los alumnos no leen, los que leen han leído siempre, pero la mayoría lee poco y lo hace para superar pruebas evaluatorias de lectura, y una buena parte no comprende lo que lee. Una situación similar ocurrió con los hallazgos de Romero-Oliva, Trigo-Ibañez y Moreno-Verdulla (2018) quienes investigaron el tránsito de la comprensión lectora a la competencia literaria y los resultados evidenciaron una necesidad de trabajar la comprensión lectora entre los estudiantes para facilitar el acceso al texto literario con el fin de desarrollar su competencia literaria. 
La evaluación de la experiencia lectora incluyó indicadores sobre selección progresiva de lecturas, acumulación de conocimientos y enriquecimiento con varios textos, en lo que se incluía lo visto y escuchado, los resultados fueron que el 67,2 \% se ubicó en el nivel bajo, el 29,3\% en el nivel alto y el 3,4 \% en el nivel medio. Estos resultados son contrarios a lo que se encontró en otras investigaciones como las de Jiménez y García (2011) investigaron para establecer los nexos de intertextualidad entre televisión, cine y publicidad, se centraron en la influencia del cine en la publicidad que se realiza a través de la televisión y encontró que, en efecto, en la publicidad existe intertextualidad con imágenes y otros referentes de las películas y cuando el espectador descubre la conexión entre película y publicidad se cierra el círculo para lo que fue creado el spot. Del mismo modo, los resultados difieren de los hallazgos de Baltodano (2009) quien realizó una investigación para establecer la relación entre la literatura y el cine en cuatro aspectos básicos y concluyó que el cine ejerce una influencia estética en las obras literarias y en el concepto tradicional de literatura.

La evaluación de ideas y valores universales incluyó indicadores sobre componente ejemplarizante y universal de la literatura que contiene los valores atemporales, asunción de postura dialéctica en el aula sobre todo para valores que están contenidos en la tradición oral; y se incluyó un indicador de interdisciplinariedad, para temas como la vida de la que se ocupan las ciencias naturales, la biología, la medicina, entre otras y cuyos elementos teóricos contribuyen al repertorio intertextual del egresado, los resultados fueron que el 70,7 \% se ubicó en el nivel bajo, lo que significa que fracasó en la identificación de valores universales en las lecturas dadas, el 20,7 $\%$ se ubicó en el nivel alto y el 8,6 \% en el nivel medio. La intemporalidad de los valores como elemento intertextual ha sido recogido también por Romero (2010) quien realizó una investigación para reflexionar sobre el fenómeno de la interpretación de la literatura en el ámbito escolar desde un análisis intertextual, los hizo desde el enfoque hermenéutico y encontró que, en toda obra literaria y en todos los tiempos, existe un componente estético implícito que puede encontrarse como una constante y que asume un valor universal y atemporal. Lo mismo encontró Martínez (2017) quien desarrolló una investigación en torno a la intertextualidad en la literatura heroica y encontró como valor atemporal, un componente marcado de valentía, arrojo y defensa de la territorialidad a cambio de la vida, concluyendo que los textos heroicos resaltan valores cívicos y militares vinculados al patriotismo.

\section{DISCUSIÓN}


El 96,6 \% de los egresados de educación básica quienes se preparan para seguir estudios superiores indicó que durante su vida escolar leyó menos de 15 textos escolares completos y en cuanto a otro tipo de libros leídos por iniciativa propia el 98,3 \% indicó que lo hizo con menos de 15 libros, lo que implica que cuando se inicie la educación superior tendrá un exiguo repertorio de intertextualidad que repercute en la comprensión, interpretación y construcción de sentido a los textos a los que acceda. Sucesivos estudios muestran que los textos están contenidos en soportes impresos, fílmicos y en la oralidad, los que generan un nodo de significados que dota al sujeto de la capacidad de entendimiento se encontró que el 29,3\% visualizó películas de contenido romántico, el 27,6\% de acción y el 12,1\% de ficción, las cuales por su naturaleza aportan poco o nada a la intertextualidad académica; respecto a la identificación del género de las obras leídas el 44,8\% dejó la pregunta sin responder por desconocimiento de su clasificación. Estos resultados son contrarios a los encontrados por Elouise Budag (2019) quien investigó la forma en la que operaba la intertextualidad en una serie televisiva dentro de la dimensión discursiva y encontró que en la mayoría de escenas se producían referencias intertextuales, por lo que afirmó que la intertextualidad no solo ocurre en el elemento discursivo sino que existe construcción y producción de escenas intertextuales, en cuya composición conviven imágenes externas e internas mediante la inserción de imágenes asociadas a los saberes que incluyen elementos imaginarios, ficticios y los roles de los agentes.

La intertextualidad como elemento de la competencia comunicativa, en el 62,1\% se ubicó en el nivel bajo, debe precisarse que el programa curricular de educación básica incorpora este elemento desde el sexto grado de primaria hasta el último de secundaria, si bien el 29,3\% se ubicó en el nivel alto, se encontró que dicho grupo accedió a sucesivas lecturas en academias extraescolares, trabajaban en librerías, se dedicaban al teatro u otro tipo de arte por lo cual no resulta atribuible a la acción educativa formal. Como señaló Tyner (2008) se accede a la intertextualidad desde recursos on-line, los que permiten flexibilidad, interactividad, análisis y producción en línea; ofrecen múltiples textos para favorecer la integración colectiva del conocimiento, permitiendo la alfabetización en intertextualidad a través de la web.

El 62,1\% en la competencia literaria, se ubicó en el nivel bajo, esta situación implica niveles bajos de atención y reflexión, pobre repertorio de saberes en los que debe anclar la comprensión del texto actual y ausencia de marco sociocultural para su interpretación. Estos resultados mantienen coherencia con los resultados de Hugo Rojas, Leiva Salum, Marchant Moreno, Gallegos Pérez y Toro Trengove (2018) quienes trabajaron intertextualidad en universitarios principiantes y encontraron uso frecuente de citas textuales y parafraseo y ausencia 
de intertextos. Estos resultados son diferentes a los que encontró Solá (2005) quien comparó la producción de dos autores sobre identidad canónica y encontró intertextualidad, aunque existían sentidos diferentes, lo que evidenciaba el particular entendimiento de cada autor determinado por su formación cultural. Los resultados de esta investigación son diferentes a los de Goswami (2019) quien investigó la postura cognitiva que adoptan los lectores ante la intertextualidad y encontró que esta no es una propiedad del texto, sino, se trata de una modalidad cognitiva de percepción.

El 67,2\% en experiencia lectora se ubicó en el nivel bajo, lo cual significa que no se seleccionan lecturas que respondan a sus intereses, esto da lugar a lecturas desarticuladas, aisladas, que no aportan a la acumulación de conocimientos y en ese sentido no existe ninguna temática que se enriquezca con dichos textos; en ese mismo sentido las películas vistas fueron de género romántico y en los textos contenidos en la oralidad no se capitalizaron los mensajes. Estos resultados son diferentes a los de Becerra (2010) quien investigó la intertextualidad en la lectura detectivesca (temática) y encontró una urdimbre compleja con situaciones de suspenso y de espera a ser resuelto; y en las que el lector con repertorio intertextual, sigue las pistas del crimen recurriendo al conocimiento de la cábala de otros autores. Estos resultados son diferentes a los de Looft (2018) quien analizó la producción de la escritora feminista Rosa Mayreder la cual empleó la intertextualidad como símbolo estratégico de resistencia y defensa de los derechos de las mujeres a la educación, los cambios generacionales, las situaciones de conflicto y cambio social. En la investigación de Li (2019) se encontró que la intertextualidad se empleó en campañas publicitarias del 2008 en la República China y funcionó para los grupos afines que compartían las mismas orientaciones y valores.

Las ideas y valores universales poseen alto contenido de intertextualidad, la defensa de la vida impregna toda producción escrita, fílmica u oral, el lector debe identificar estos elementos en el texto; se encontró que el 70,7 \% se ubicó en el nivel bajo lo que refleja que no pudo precisarse estos elementos. Estos resultados difieren de los hallazgos de Haixia Yang y Liqing Kang (2019) quienes conjuntamente con eruditos en narrativa, trabajaron la intertextualidad en el cuento de hadas de Blancanieves y encontraron la influencia de la novela del mismo nombre escrita 152 años antes, por lo que concluyeron que las diferencias en las traducciones estaban en función al género atribuido y las variantes lingüísticas del traductor. Los resultados de esta investigación son diferentes a los de Schöngut Grollmus y Pujal Llombart (2014) quienes eligieron textos de perspectiva feminista para aproximarse a la intertextualidad en el dolor crónico desde la perspectiva de género y precisaron que tanto el dolor como el género son términos y además son actos del lenguaje cuya existencia es anterior al relato y a la narrativa y seguirán existiendo y 
Graham (2000) agregó que la escritura está hecha de pedazos de la realidad social y refleja las tensiones propias de la ideología.

\section{REFERENCIAS BIBLIOGRÁFICAS}

Aguilar, L. E. (2008). Lecturas transversales para formar receptores críticos. Comunicar, XVI (31), 27-33.

Amoretti, M. (1996). La intertextualidad: un ensayo metacrítico. Filología y Lingüística XXII (2): 07-14, 1996

Arrieta, D. (2015). Intertextualidad, dialogismo y poética cognitiva en la novela contemporánea: Bernardo Carvalho, Eduardo Lago y Mario Bellatín. España: Universidad Complutense de Madrid.

Baltodano, G. (2009). La literatura y el cine: una historia de relaciones. Costa Rica: Universidad Nacional de Costa Rica.

Barthes, R. (2002). El susurro del lenguaje. Más allá de la palabra y de la escritura. Barcelona: Paidós.

Batjin, M. (1986). Speech Genres and Other Late Essays. Austin: U. de Texas.

Becerra, J. (2010). Intertextualidad y lectura detectivesca en "Como el aire de abril", de Arturo Echavarría. Revista Nuestra América, (8), 183-204. Retrieved from http://search.ebscohost.com/login.aspx?direct=true \&db=fua\&AN=57310661\&lang=es\&s ite=ehost-live

Buckingham, D. (2004). Educación en medios. Alfabetización, aprendizaje y cultura contemporánea. Barcelona: Paidós- Comunicación.

Carbonell, D. (2002). La intertextualidad. Tesis de Maestría. Cuba: La Habana.

de Vicente-Yagüe, M. I. y Guerrero, P. (2014). Fundamentación teórica de la intertextualidad literario-musical como línea de investigación e innovación en Didáctica de la Lengua y la Literatura. España: Universidad de Murcia

Díaz, E. M. (2009). Una propuesta didáctica: intertextualidad e interdisciplinaridad en las Danzas de la muerte medievales. España: Universidad de Santiago de Compostela.

Dilthey, W. (1986). Introducción a las ciencias del espíritu. Ensayo de una fundamentación del estudio de la sociedad y de la historia. España: Alianza Universidad.

Elouise Budag, F. (2019). Intertextualidade e cultura material: um estudo de narrativa ficcional audiovisual contemporânea. Chasqui (13901079), (140), 337-354. Retrieved from http://search.ebscohost.com/login.aspx?direct=true \&db=fua\&AN=138163829\&lang=es\& site $=$ ehost-live

García, D. J. (2017). La intertextualidad de Una impecable soledad de Luis Hernández. (Tesis de licenciatura). Perú: Pontificia Universidad Católica del Perú.

Genette, G. (1972) "Discours du récit." En Genette, Figures III. París: Seuil, 1972. 67-282.

Gonzalez, J. (2012) Intertextualidad y desarrollo de competencias comunicativas y narrativas. Revista Iberoamericana de Educación $n .^{\circ}$ 60/3 - 15/11/12

Goswami, S. (2019). Nature of Intertextuality in the Poems of Jibanananda Das: A Cognitive Poetics Approach. Language in India, 19(6), 386-395. Retrieved from http://search.ebscohost.com/login.aspx?direct=true \&db=cms\&AN=137177631\&lang=es $\underline{\text { site }=\text { ehost-live }}$

Graham, A. (2000). Intertextuality. Londres, Nueva York: Routledge.

Guillén, C. (1985). Entre lo uno y lo diverso. Introducción a la literatura comparada. Barcelona: Crítica.

Haixia Yang1, \& Liqing Kang1. (2019). Multidimensional Reading of Snow White in China. Journal of Language Teaching \& Research, 10(6), 1356-1361. https://doi.org/10.17507/jltr.1006.27

Hanson, C. y Gurr, A. (1981). Katherine Mansfield. London: Macmillan. 
Hugo Rojas, E., Leiva Salum, N., Marchant Moreno, M., Gallegos Pérez, C., \& Toro Trengove, P. (2018). Intertextualidad manifiesta en textos de estudiantes universitarios. Caracterización de las citas en una etapa de formación académica inicial. Onomázein, 41, 29-56. https://doi.org/10.7764/onomazein.41.10

Kasper, L. \& Singer R. (1997). Reading, Language Acquisition, and Film Strate- gies. PostScript, 15, pp. 5-7. En: World Wide Web: http://lkasper.tripod.com/ postscript.html

Informe de evaluación de Lectura en sexto grado - 2013 ¿Qué logros de aprendizaje en Lectura muestran los estudiantes al finalizar la primaria? (2013). Serie aportes pedagógicos. Perú: UMC-Ministerio de Educación.

Jiménez, G. y García, M. C. (2011). La intertextualidad en televisión: cine y publicidad. Revista Razón y Palabra, vol. 17, núm. 79, mayo-julio, 2012. Instituto Tecnológico y de Estudios Superiores de Monterrey, Estado de México.

Li, S. (2019). Intertextuality as a strategy of glocalization: A comparative study of Nike's and Adidas's 2008 advertising campaigns in China. DO - 10.1515/sem-2017-0134

Looft, R. (2018). Intertextuality as Power: Rosa Mayreder's Response to Goethe's Faust and the Cult of Male Genius. Journal of Austrian Studies, 51(2), 73-87. https://doi.org/10.1353/oas.2018.0022

Lotman, Y. M. (1996). La semiosfera I. Semiótica de la cultura y del texto. Madrid: Cátedra.

Maracara, C. I. (2001). Intertextualidad, subalternidad e ironía: La obra de Carlos Monsiváis. (Tesis doctoral). España: Universidad Autónoma de Barcelona.

Martín-Barbero, J. y Rey, G. (1999). Los ejercicios del ver. Hegemonía audiovisual y ficción televisiva. Barcelona: Gedisa.

Martínez, C. A. (2017). Intertextualidad en la literatura heroica, una herramienta eficaz para un lector competente. Colombia: Universidad Distrital Francisco José de Caldas.

Martínez, M. del C. (2017). Intertextualidad en la obra narrativa de Miguel Espinosa. De Escuela de mandarines a Tríbada. España: Universidad de Sevilla. Recuperado de https://idus.us.es/bitstream/handle/11441/70544/Tesis\%20M\%20Espinosa\%20defendida. pdf? sequence $=5 \&$ isAllowed $=y$

Mendoza Fillola, A. (2004). La educación literaria. Bases para la formación de la competencia lecto-literaria, Archidona (Málaga): Aljibe.

Ministerio de Educación -Minedu (2016a). Programa curricular de educación primaria. Perú. Recuperado de www.minedu.gob.pe

Ministerio de Educación -Minedu (2016b). Programa curricular de educación secundaria. Perú. Recuperado de www.minedu.gob.pe

Montaño, J. R. (2002). La intertextualidad. Cuba: Conferencia. La Habana.

Navarro, M. E. (2015). La Intertextualidad, Literatura y Bellas Artes en José Lucas: una investigación de enfoque analítico-semiótico. (Tesis doctoral). España: Universidad de Murcia. Recuperado de https://tesisenred.net/handle/10803/307538\#page=1

Níkleva, D. G. (2013). La intertextualidad entre lengua y artes en la enseñanza de idiomas. Onomázein, 27, 107-120. Retrieved from http://search.ebscohost.com/login.aspx?direct=true \&db=fua\&AN=94594657\&lang=es\&s ite $=$ ehost-live

Romero (2010). Estética e intertextualidad de la literatura Una invitación a reconocer la voz del lector en el aula. Colombia: Universidad Nacional de Colombia.

Romero, K. y Fierro, B. (2016). La intertextualidad y la enseñanza de la literatura en preuniversitario. Atenas, 1(33).

Romero-Oliva, M. F., Trigo-Ibañez, E. y Moreno-Verdulla, P. (2018). De la comprensión lectora a la competencia literaria a través de la obra de Eliacer Cansino. OGNOS. Revista de estudios sobre lectura, 17(3). 
Sánchez, G. B. (2016). La intertextualidad y sus implicaciones en el proceso lector. España: Universidad de Alicante. Recuperado de https://dialnet.unirioja.es/servlet/tesis?codigo $=58992$

Schöngut Grollmus, N., \& Pujal i. Llombart, M. (2014). Narratividad E Intertextualidad Como Herramientas Para El Ejercicio De La Reflexividad en La Investigación Feminista: El Caso Del Dolor Y El Género. Athenea Digital (Revista de Pensamiento e Investigación Social), 14(4), 89-112. https://doi.org/10.5565/rev/athenea.1373

Solá, D. (2005). En busca de un discurso identitario y canónico: La rescritura de Rhys y Coetzee en Wide Sargasso Sea y Foe. (Tesis de doctorado). España: Universidad de Pompeu Fabra.

Tyner, K. (2008). Audiencias, intertextualidad y nueva alfabetización en medios. (Spanish). Comunicar, 16(30), 79-85. Retrieved from http://search.ebscohost.com/login.aspx?direct=true\&db=eue\&AN=34536638\&lang=es\&s ite=ehost-live

Vega, C. (2017). El desarrollo de la competencia literaria desde una perspectiva hermenéutica: entornos participativos y convergencia cultural en las aulas de secundaria. Ecuador: Universidad de la Rioja

Conflicto de intereses / Competing interests:

Los autores declaran que no incurren en conflictos de intereses.

Rol de los autores / Authors Roles:

Fernando Ledesma: conceptualización, curación de datos, análisis formal, adquisición de fondos, investigación, metodología, administración del proyecto, recursos, software, supervisión, validación, visualización, escritura preparación del borrador original, escritura - revisar \& amp; edición.

Juana Cruz: conceptualización, análisis formal, investigación, metodología, administración del proyecto, recursos, software, supervisión, validación, visualización, escritura - preparación del borrador original, escritura - revisar \& amp; edición.

María Caycho: conceptualización, investigación, metodología, administración del proyecto, recursos, software, supervisión, validación, visualización, escritura - preparación del borrador original, escritura - revisar \& amp; edición.

Renee Rosales: conceptualización, investigación, metodología, administración del proyecto, recursos, software, supervisión, validación, visualización, escritura - preparación del borrador original, escritura - revisar \& amp; edición.

\section{Fuentes de financiamiento / Funding:}

Los autores declaran que no recibieron un fondo específico para esta investigación.

\section{Aspectos éticos / legales; Ethics / legals:}

Los autores declaran no haber incurrido en aspectos antiéticos, ni haber omitido aspectos legales en la realización de la investigación. 